\title{
Review
}

\section{The Alliance AMBUSH Trial: Rationale and Design}

\author{
Anita Mahajan ${ }^{1, *}$, Helen Shih ${ }^{2}$, Marta Penas-Prado ${ }^{3}$, Keith Ligon ${ }^{4}$, Kenneth Aldape ${ }^{5}$, Leland S. Hu ${ }^{6}$, \\ Ashlee R. Loughan ${ }^{7}$, Michael R. Basso ${ }^{8}$, Heather E. Leeper ${ }^{3}$, Brian V. Nahed ${ }^{9}$, Shannon L. Stott ${ }^{10}$, Susan Geyer ${ }^{11}$, \\ Caterina Giannini ${ }^{12,13}$ and Evanthia Galanis ${ }^{14}$
}

check for

updates

Citation: Mahajan, A.; Shih, H.;

Penas-Prado, M.; Ligon, K.; Aldape, K.; Hu, L.S.; Loughan, A.R.; Basso, M.R.; Leeper, H.E.; Nahed, B.V.; et al. The Alliance AMBUSH Trial:

Rationale and Design. Cancers 2022, 14, 414. https://doi.org/10.3390/ cancers14020414

Academic Editor: André Oscar von Bueren

Received: 23 November 2021

Accepted: 6 January 2022

Published: 14 January 2022

Publisher's Note: MDPI stays neutral with regard to jurisdictional claims in published maps and institutional affiliations.

Copyright: (C) 2022 by the authors. Licensee MDPI, Basel, Switzerland. This article is an open access article distributed under the terms and conditions of the Creative Commons Attribution (CC BY) license (https:// creativecommons.org/licenses/by/ $4.0 /)$.
1 Department of Radiation Oncology, Mayo Clinic, Rochester, MN 55905, USA

2 Department of Radiation Oncology, Massachusetts General Hospital, Boston, MA 02114, USA; HSHIH@mgh.harvard.edu

3 Neuro-Oncology Branch, National Cancer Institute, National Institutes of Health, Bethesda, MD 20892, USA; marta.penas-prado@nih.gov (M.P.-P.); heather.leeper@nih.gov (H.E.L.)

4 Department of Pathology, Brigham and Women's Hospital, Boston, MA 02115, USA; Keith_Ligon@dfci.harvard.edu

5 Laboratory of Pathology, National Cancer Institute, Bethesda, MD 20892, USA; kenneth.aldape@nih.gov

6 Department of Radiology, Mayo Clinic, Phoenix, AZ 85054, USA; hu.leland@mayo.edu

7 Department of Neurology, Virginia Commonwealth University, Richmond, VA 23284, USA; ashlee.loughan@vcuhealth.org

8 Department of Psychiatry and Psychology, Mayo Clinic, Rochester, MN 55905, USA; basso.michael@mayo.edu

9 Department of Neurosurgery, Massachusetts General Hospital, Boston, MA 02114, USA; BNAHED@MGH.HARVARD.EDU

10 Center for Cancer Research, Massachusetts General Hospital, Boston, MA 02114, USA; sstott@mgh.harvard.edu

11 Department of Quantitative Health Sciences, Mayo Clinic, Rochester, MN 55905, USA; geyer.susan@mayo.edu

12 Department of Pathology, Mayo Clinic, Rochester, MN 55905, USA; giannini.caterina@mayo.edu

13 Department of Biomedical and Neuromotor Sciences, University of Bologna, 40126 Bolgona, Italy

14 Department of Oncology, Mayo Clinic, Rochester, MN 55905, USA; galanis.evanthia@mayo.edu

* Correspondence: mahajan.anita@mayo.edu

Simple Summary: Medulloblastoma, the most common embryonal tumor in children, can also arise in older patients. Clinical studies in children with medulloblastoma have increased our understanding of molecular pathways and improved treatment strategies. We now know that medulloblastoma has at least four subtypes and each maybe best suited to specific therapies. The sonic hedgehog (SHH) pathway is altered in a significant proportion of older patients with medulloblastoma. The Alliance for Clinical Trials in Oncology cooperative group is developing the AMBUSH trial: Comprehensive Management of Adolescent and Young Adult (AYA) and Adult Patients with Medulloblastoma or Pineal Embryonal Tumors With A Randomized Placebo Controlled Phase II Focusing on Sonic Hedgehog Pathway

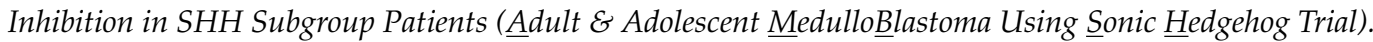
The trial gives treatment directions for all patients and randomizes patients with average risk $\mathrm{SHH}-$ activated medulloblastoma to maintenance sonidegib, a hedgehog signaling pathway inhibitor, or placebo. This trial will establish a baseline for future trial comparison and investigate the benefit of a novel targeted agent.

Abstract: Unlike medulloblastoma (MB) in children, robust prospective trials have not taken place for older patients due to the low incidence of MB in adults and adolescent and young adults (AYA). Current MB treatment paradigms for older patients have been extrapolated from the pediatric experience even though questions exist about the applicability of these approaches. Clinical and molecular classification of MB now provides better prognostication and is being incorporated in pediatric therapeutic trials. It has been established that genomic alterations leading to activation of the sonic hedgehog $(\mathrm{SHH})$ pathway occur in approximately $60 \%$ of $\mathrm{MB}$ in patients over the age of 16 years. Within this cohort, protein patched homolog (PTCH) and smoothened (SMO) mutations are commonly found. Among patients whose tumors harbor the $\mathrm{SHH}$ molecular signature, it is estimated that over $80 \%$ of patients could respond to $\mathrm{SHH}$ pathway inhibitors. Given the advances in the understanding of molecular subgroups and the lack of robust clinical data for adult/AYA MB, 
the Alliance for Clinical Trial in Oncology group developed the AMBUSH trial: Comprehensive Management of AYA and Adult Patients with Medulloblastoma or Pineal Embryonal Tumors with a Randomized Placebo Controlled Phase II Focusing on Sonic Hedgehog Pathway Inhibition in SHH

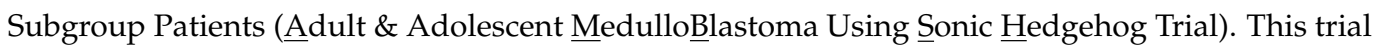
will enroll patients 18 years of age or older with MB (any molecular subgroup and risk stratification) or pineal embryonal tumor. Patients will be assigned to one of three cohorts: (1) average risk nonSHH-MB, (2) average risk SHH-MB, and (3) high risk MB or pineal embryonal tumors. All patients will receive protocol-directed comprehensive treatment with radiation therapy and chemotherapy. Patients with SHH-MB in cohort 1 will be randomized to a smoothened inhibitor or placebo as maintenance therapy for one year.

Keywords: medulloblastoma; sonic hedgehog; sonidegib; pineal parenchymal tumor; clinical trial; radiotherapy; targeted therapy

\section{Introduction}

Medulloblastoma (MB) is the most common malignant brain tumor of childhood, yet it accounts for only $1 \%$ of adult brain tumors [1,2]. Despite this low incidence, $30 \%$ of all medulloblastoma cases are diagnosed in individuals between age 15 and 39, patients who often have limited access to clinical trials. Over the past several decades, sequential cooperative group non-infant pediatric MB studies have resulted in better outcomes with a multidisciplinary approach incorporating surgery, comprehensive radiation, and multiagent chemotherapy.

After complete staging evaluation patients are found to either average- or high-risk groups. Patients with average-risk disease have neither residual disease (i.e., $\leq 1.5 \mathrm{~cm}^{2}$ ) nor metastatic disease, (i.e., M0). All others are staged into the high-risk group. In addition, it has been noted the presence of anaplasia or MYC amplification even with a complete resection and $\mathrm{M} 0$ disease are associated with poorer outcomes. These patients are often assigned to the high-risk group. Currently, based on several multi-institutional trials, pediatric patients with average-risk and high-risk MB have an estimated 5-year overall survival of $85 \%$ and $50-75 \%$, respectively [3-8].

Unfortunately, due to the low incidence of the disease adult MB treatment paradigms have been challenging to establish. Pediatric data have been extrapolated to the older population, but concerns exist regarding the differences in tumor biology and treatment tolerance. Adult MB may represent a different biological spectrum than children, but many characteristics are also shared thus there is uncertainty of the validity of paradigms from the pediatric experience in an older population [9-12].

Over the last 10 years MB has become recognized as a heterogeneous disease with important biologic, molecular and clinical risk factors. The basic subgroups are Wingless/Integrated-activated (WNT), Sonic Hedgehog-activated (SHH), Group 3 and Group 4, each with a characteristic age spectrum and disease outcome [13-16]. The distribution of molecular subgroups in adults and children varies: $60-70 \%$ of adult MB have an aberrant activation of the SHH pathway, as compared to only $30 \%$ in children [17-19]. The subgroup $3 \mathrm{MB}$ represent about $25 \%$ of cases in children, but are not common in adults, whereas the WNT and Group 4 tumors appear to have a worse outcome in adults than in children based on retrospective data. Finally, the frequency of high-risk metastatic disease (i.e., disseminated outside of the posterior fossa and/or systemically) at initial presentation is lower in adults than in children [20-22].

The Alliance for Clinical Trial in Oncology group is planning the AMBUSH trial: Comprehensive Management of Adolescent and Young Adult (AYA) and Adult Patients with Medulloblastoma or Pineal Embryonal Tumors with a Randomized Placebo Controlled Phase II Focusing on Sonic Hedgehog Pathway Inhibition in SHH Subgroup Patients

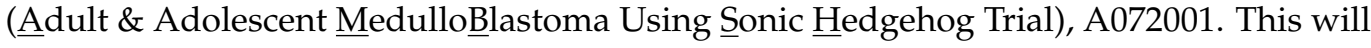


be a comprehensive trial that includes all patients 18 and older with medulloblastoma or pineal embryonal tumors divided into three cohorts: (1) average-risk non-SHH-MB, (2) average-risk SHH-MB, and (3) high-risk MB or pineal embryonal tumors. All eligible patients will receive protocol directed comprehensive treatment with radiation therapy and chemotherapy. Patients with SHH-MB in cohort 1 will be randomized to a smoothened inhibitor or placebo as maintenance therapy for one year. This protocol once completed will provide robust guidance for the management of medulloblastoma and pineal embryonal tumors in the non-pediatric population.

\section{Classification of Medulloblastoma}

The 2021 WHO classification for MB requires distinction of SHH- and WNT MB from non-WNT/non-SHH tumors. Pediatric MB paradigms now incorporate biologic in addition to clinical prognostic factors with the following goals: (1) toxicity reduction for very low risk disease (WNT+, M0) by reduction in RT dose to the CSI and the primary site, (2) improved tumor control strategies for patients with high-risk disease (metastatic disease, anaplastic $\mathrm{MB}$, myc amplification, Group 3 and 4 or non WNT/SHH) using high dose chemotherapy and/or varying systemic agents. NCT00392327, NCT01878617, and NCT02724579).

In this study, we will incorporate upfront classification of MB subtype by integral centrally performed molecular analysis including immunohistochemistry, copy number assessment, and DNA sequencing for cohort assignment and randomization. Prospective genome-wide DNA methylation profiling will also be performed to fully characterize each tumor and confirm classification before randomization.

\section{Rationale to Include Non-SHH-MB, High-Risk MB, and Pineal Tumors}

The intent of this unique trial is to leverage the opportunity and gain knowledge on all other populations of adult/AYA patients with MB (non-SHH and/or high risk) and pineal embryonal tumors since the treatment platform for all these subgroups is like the one proposed for the randomized group. Brandes et al., reported on 36 adult patients, 11 of whom had M+ disease, treated over a 12-year span. In this study the PFS for adult patients was similar to similarly staged pediatric patients with high-risk disease having a poorer outcome [12]. Herrlinger et al., reported on a retrospective study of 36 adult patients treated over 22 years with $\mathrm{MB}$ and supratentorial primitive neuroectodermal tumors and noted that chemotherapy appeared to prolong survival [23]. The authors concluded more study was required and future efforts may build on this experience with the addition of new knowledge from ongoing and completed pediatric trials.

Because the natural history and treatment paradigms for pineal parenchymal tumors of intermediate differentiation (PPTID) vary from poorly/undifferentiated pineal parenchymal tumors, patients with PPTID will not be eligible [24]. Patients with non-SHH-MB, high-risk $\mathrm{MB}$ or pineal embryonal tumors will be enrolled on non-randomized arms and treated in a prescribed manner to determine objective outcomes since robust prospective data are not available for these patients. All patients with pineal region embryonal tumors will undergo full molecular characterization to establish prospective information for future analysis.

Non-randomized study objectives for this group will be to characterize clinical outcomes for pineal embryonal tumors and high-risk MB with comprehensive radiotherapy followed by adjuvant chemotherapy in a prospective trial setting. Further, in this rare disease setting of adult $\mathrm{MB}$ and pineal embryonal tumors patients, establishing a prospectively and rigorously collected set of data on a cohort treated with the current standard of care facilitates its potential use as external or 'synthetic' controls when evaluating experimental regimens in this same rare disease setting. 


\section{Backbone of AMBUSH Therapeutic Strategy}

\subsection{Surgery}

Surgical intervention for posterior fossa tumors is important to re-establish CSF flow when there is obstructive hydrocephalus, to provide tissue diagnosis, and to decompress in the setting of mass effect. It has been noted in several MB studies that a complete resection has prognostic implication $[8,25,26]$. In our study, the degree of resection will be used for cohort assignment, where those with residual tumor greater than $1.5 \mathrm{~cm}^{2}$ on cross sectional measurement will be assigned to the high-risk arm. The degree of resection will be evaluated as an independent factor on disease outcomes including local recurrence and disease control. We will also assess for drop metastases along the spinal axis to further stratify eligibility and survival outcomes.

\subsection{Radiotherapy}

After studying post mortem MB failure patterns, Paterson and Farr recommended irradiating the brain and spinal cord in one undivided volume in the 1940s [27]. Their publication in 1953 reported the outcomes of 22 children and five adults in whom 65\% had 3-year overall survival (OS). Craniospinal irradiation (CSI) has become part of the standard of care for treatment of MB with curative intent. The CSI dose in this early study was 3000-3500 roentgen to the spine and a maximum of 5000 roentgen to the cerebellum, with the limit set by tolerance of the normal tissues. Of note, a pediatric study (POG8631/CCG923) randomized pediatric patients with average risk MB to radiation therapy alone of 23.4 Gy CSI vs. 36 Gy CSI, both with a posterior fossa boost to 54 Gy, and reported an 8-year event-free survival (EFS) of 52\% vs. 67\%, respectively [8]. The standard CSI dose for average risk MB CSI remained 36 Gy when used without chemotherapy. Currently for patients 18 years and younger with average-risk disease, 23.4 Gy CSI with adjuvant chemotherapy is the standard of care with similar outcomes to 36Gy CSI without chemotherapy.

In adults, data for the use of lower dose CSI with chemotherapy is limited. Friedrich et al. reported a 4-year EFS of $68 \%$ and 4-year OS of $89 \%$ with no difference between 23.4 Gy CSI $(n=9)$ and 35.2 Gy CSI $(n=47)$ on the HIT 2000 prospective observational study [28]. Massimino et al., reported on 44 adults with non-metastatic MB treated at two European centers treated with <36 Gy CSI and chemotherapy. Thirty-six patients received 23.4 Gy CSI and eight patients had 30.6 Gy CSI in addition to a posterior fossa boost and chemotherapy based on pediatric protocols at each institution. The 5- and 10-year progression-free survival (PFS) was $82.2 \%$ and $78.5 \%$, respectively. The OS rates were $89 \%$ and $75.2 \%$ at 5 and 10 years [26]. Similarly, Majd et al., published a large retrospective single institution study of adult MB in which 16 of 53 patients with standard-risk MB received $<30$ Gy CSI and no difference in outcome was noted [29].

A transition from a boost to the entire posterior fossa to a conformal boost of the primary site surgical bed has taken place as more conformal radiotherapy techniques have become available. The benefit has been lower dose to the cochlea, brainstem, spinal cord, and supratentorial brain. Michalski et al., reported the results of COG ACNS 0331 that randomized 464 children with average-risk MB to whole posterior fossa vs. involved field boosts with 5-year EFS $80.5 \%$ vs. $82.5 \%$, respectively [7].

Based on these data and the investigators pooled experiences, in this study, 23.4 Gy CSI followed by a $30.6 \mathrm{~Gy}$ boost to the primary site will be used for all patients with averagerisk disease. For all high-risk patients, the CSI dose will be $36 \mathrm{~Gy}$ followed by boost (s) to the primary (54 Gy) and metastatic (45-54 Gy) sites. All patients will receive adjuvant chemotherapy and high-risk patients will receive concurrent vincristine during CSI.

\subsection{Chemotherapy}

Adults do not tolerate chemotherapy as well as children as noted by several groups. Adult patients experience prolonged neutropenia, increased neuropathy, and require dose modifications or chemotherapy cessation due to toxicities $[28,30,31]$. There is no agreement 
on the optimal chemotherapy regimen for medulloblastoma in adults; chemotherapy regimens frequently used in clinical trials for average- and high-risk disease are summarized in Tables 1 and 2. The proposed regimen using cisplatin, vincristine, and cyclophosphamide is the result of an in-depth discussion within the neuro-oncology committee of Alliance that represents most major academic centers in the US and the NCI Connect adult MB workshop [11]. Our hypothesis is that the use of an SHH inhibitor will allow chemotherapy de-escalation in patients with the appropriate molecular characteristics.

Table 1. Chemotherapy agents that are used in the treatment in average-risk medulloblastoma with final AMBUSH regimen in comparison to other recently reported and ongoing trials.

\begin{tabular}{|c|c|c|c|c|c|c|c|}
\hline Tx Phase & CHEMO & AMBUSH & A9961 & ACNS0331 & NOA-7 & SJMB03 & SJMB12 \\
\hline & $\begin{array}{l}\text { Number of } \\
\text { cycles, (doses } \\
\left.\mathrm{mg} / \mathrm{m}^{2}\right)\end{array}$ & $\begin{array}{l}6 \text { cycles as } \\
\text { tolerated }\end{array}$ & $\begin{array}{c}\text { A } 8 \\
\text { (ccnu/cis/vcr) } \\
\text { vs. } \\
\text { B } 8 \\
(\mathrm{cpm} / \mathrm{cis} / \mathrm{vcr})\end{array}$ & $\begin{array}{c}\text { A } 6 \\
\text { (ccnu/cis/vcr) } \\
\text { B 3 } \\
(\mathrm{cpm} / \mathrm{vcr}) \\
\text { AAB }\end{array}$ & ADULT & $\begin{array}{c}\text { A } 4 \\
(\mathrm{vcr} / \mathrm{cpm} / \mathrm{cis})\end{array}$ & $\begin{array}{c}\text { A } 4 \\
(\mathrm{vcr} / \mathrm{cpm} / \mathrm{cis})\end{array}$ \\
\hline$\underline{\underline{\sim}}$ & VCR & None & $8(1.5)$ & $6(1.5)$ & $3(1.5)$ & none & none \\
\hline \multirow{5}{*}{ 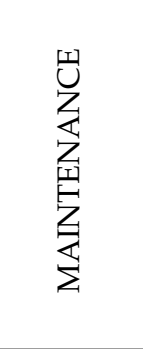 } & VCR & $\begin{array}{c}6(1.5 \times 2) \\
\max (2) \mathrm{mg}\end{array}$ & $8(1.5 \times 3)$ & $\begin{array}{c}\text { A } 6(1.5 \times 3) \\
+ \\
\text { B } 3(1.5 \times 2)\end{array}$ & $6(1.5 \times 2)$ & $4(1.0 \times 2)$ & $4(1.0 \times 2)$ \\
\hline & CIS & $6(75)$ & $8(75)$ & A 6 (75) & $6(70)$ & $4(75)$ & $4(75)$ \\
\hline & $\mathrm{CCNU}$ & none & $8(75)$ & A 6 (75) & $6(75)$ & none & none \\
\hline & CPM & $6(1000 \times 2)$ & $8(1000 \times 2)$ & B $3(1000 \times 2)$ & none & $4(2000 \times 2)$ & $4(1500 \times 2)$ \\
\hline & VP16 & none & none & none & none & none & none \\
\hline \multicolumn{2}{|c|}{ Comments } & $\begin{array}{l}6 \text { cycles if } \\
\text { tolerated }\end{array}$ & $\operatorname{reg} A=B$ & std COG & tolerated & $\begin{array}{l}\text { stem cell } \\
\text { rescue } \times 4\end{array}$ & $\begin{array}{c}\text { SHH: } \\
\text { vismodegib } \\
\text { maintenance }\end{array}$ \\
\hline
\end{tabular}

Abbreviations: Tx: Treatment; CHEMO: chemotherapy; VCR: vincristine; CIS: cisplatin; CPM: cyclophosphamide; VP16: etoposide. COG: Children's Oncology Group; Trial Sponsors: A9961: Pediatric Oncology Group; ACNS033: COG; NOA-7: German Neuro-Oncology Working Group; SJMB03 and SJMB12: St Jude Children's Research Hospital.

Table 2. Chemotherapy agents that are used in the treatment in high-risk risk MB with final AMBUSH regimen in comparison to other recently reported and ongoing trials.

\begin{tabular}{|c|c|c|c|c|c|c|}
\hline Tx Phase & CHEMO & AMBUSH & ACNS 0332 & SJMB03 & SJMB12- SHH & SJMB12 \\
\hline & $\begin{array}{c}\text { All doses } \\
\mathrm{mg} / \mathrm{m}^{2}\end{array}$ & $\begin{array}{l}6 \text { cycles as } \\
\text { tolerated }\end{array}$ & 6 cycles & 4 (vcr/cpm/cis) & 4 (vcr/cpm/cis) & $\begin{array}{c}\text { A } 4 \text { (vcr } / \mathrm{cpm} / \mathrm{cis}) \\
\text { B } 3 \text { (paclitaxel/gem) } \\
\text { AABAABB }\end{array}$ \\
\hline \multirow[t]{2}{*}{$\underline{\underline{w}}$} & VCR & $\begin{array}{l}6(1.5) \\
\text { q2 wk }\end{array}$ & 6 (1.5) weekly & none & none & none \\
\hline & Carboplatin & none & 30 (35) daily & none & none & none \\
\hline \multirow{5}{*}{ 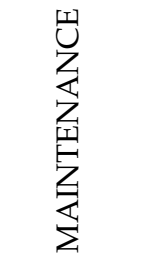 } & VCR & $6(1.5 \times 2)$ & $6(1.5 \times 2)$ & $4(1.0 \times 2)$ & $4(1.0 \times 2)$ & $4(1.0 \times 2)$ \\
\hline & CIS & $6(75)$ & $6(75)$ & $4(75)$ & $4(75)$ & $4(75)$ \\
\hline & CPM & $6(1000 \times 2)$ & $6(1000 \times 2)$ & $4(2000 \times 2)$ & $4(1500 \times 2)$ & $4(1500 \times 2)$ \\
\hline & Paclitaxel & none & none & none & none & $3(600 \times 2)$ \\
\hline & Gemcitibine & none & none & none & none & $3(1250 \times 2)$ \\
\hline \multicolumn{2}{|c|}{ COMMENTS } & $\begin{array}{c}6 \text { cycles } \\
\text { if tolerated }\end{array}$ & $\begin{array}{l}\text { daily carbo } \\
\text { randomized }\end{array}$ & $\begin{array}{l}4 \times \text { stem } \\
\text { cell rescue }\end{array}$ & $\begin{array}{l}\text { vismodegib } \\
\text { maintenance }\end{array}$ & $\begin{array}{c}\text { intermediate, HR } \\
\text { Non-SHH }\end{array}$ \\
\hline
\end{tabular}


For high-risk disease, since their outcomes are less well known and tend to be worse, the AMBUSH study will maintain the use of vincristine during radiotherapy every two weeks and adjuvant chemotherapy as noted below in Table 2.

\subsection{Targeted Therapy}

The Hedgehog $(\mathrm{Hh})$ pathway is essential in embryonic development and tumorigenesis. $\mathrm{SHH}$ is an extracellular Hh protein that is involved in nervous system development. The normal SHH pathway includes transmembrane protein, PTCH which constitutively inhibits SMO, another transmembrane protein, from internalization. If SHH binds with PTCH then, PTCH and SMO are internalized, resulting in decoupling of GLI (glioma-associated oncogene) from SUFU (negative regulator suppressor of fused). GLI then triggers transcription of hedgehog factors involved with growth. PTCH or SMO mutations can result in unopposed Hh pathway activation resulting in unregulated growth [32,33].

It has been established that $\mathrm{SHH}$ pathway mutations occur in approximately $60 \%$ of $\mathrm{MB}$ in patients over the age of 16, i.e., the AYA and adult populations. Unlike younger patients where GLI, SUFU, MYCN, and TP53 mutations are noted, MB in older patients is commonly associated with PTCH and SMO mutations [17-19]. With this molecular signature, over $80 \%$ of patients could respond to $\mathrm{SHH}$ pathway inhibitors [34]. Kieran et al., evaluated sonidegib in a phase II study for 60 pediatric patients with relapsed solid tumors $(39 \mathrm{MB})$ and 16 adults with relapsed MB. In this study, five of the 10 patients with an activated Hh pathway (SHH-MB) demonstrated a complete or partial response. None of the 50 patients with a negative $\mathrm{Hh}$ signature responded [35]. Given this background and promising preliminary results, a randomized trial to evaluate the effect of SHH pathway inhibition in AYA and adult MB with SHH mutations is needed.

The primary objective in the AMBUSH trial will be to evaluate the use of sonidegib, a SMO inhibitor randomized to placebo as maintenance after completion of CSI and chemotherapy in patients with average-risk SHH-MB, who represent an enriched population of MB with SHH pathway mutations at the level or upstream of SMO.

Based on pharmacokinetic studies it is known that sonidegib has an estimated halflife of 28 days and reaches a steady state level after 4 months. The BOLT study studied sonidegib for patients (median age 65) with advanced or metastatic basal cell carcinoma [36]. Patients were randomized to sonidegib at $200 \mathrm{mg}(n=79)$ vs. $800 \mathrm{mg}(n=151)$ daily and had a median duration of exposure of 11 months and 6.6 months, respectively. Overall, discontinuation was due to a variety of issues including $40 \%$ due to adverse events, $16 \%$ due to progressive disease, $34 \%$ due to physician or patient choice. In the whole group, the median duration of response was greater than 2 years and disease control rate was over $90 \%$.

In the Kieran study, the median duration of exposure ranged from 34-511 days (median 97 days). Six out of 16 patients experienced grade 3/4 toxicities: 5 CPK, 1 AST, 2 ALT elevations. The authors recommended $680 \mathrm{mg} / \mathrm{m}^{2}$ as a single daily dose [35]. For our study we have chosen a flat dose of $600 \mathrm{mg}$ /day based on the data summarized above, toxicity profiles, and the biodistribution differences between the CNS and skin. In addition, we have institutional experience (MGH-Shih) for tolerance and efficacy.

\section{Trial Design}

The overall schema of the AMBUSH trial is shown in Figure 1. Patients will be registered and the diagnosis of either MB or pineal parenchymal tumor will be confirmed by initial central pathology review. Following full clinical review, immunohistochemistry, DNA sequencing, copy number assessment, and genome-wide DNA methylation studies, patients will be assigned to either cohort 1 or 2 and their eligibility for randomization will be determined. Cohort 1 will receive CSI 23.4 Gy CSI followed by a tumor bed boost, whereas the higher-risk cohort 2 will receive CSI 36 Gy. Only patients with average-risk SHH-MB will be randomized to sonidegib or placebo as maintenance after completing chemotherapy. 


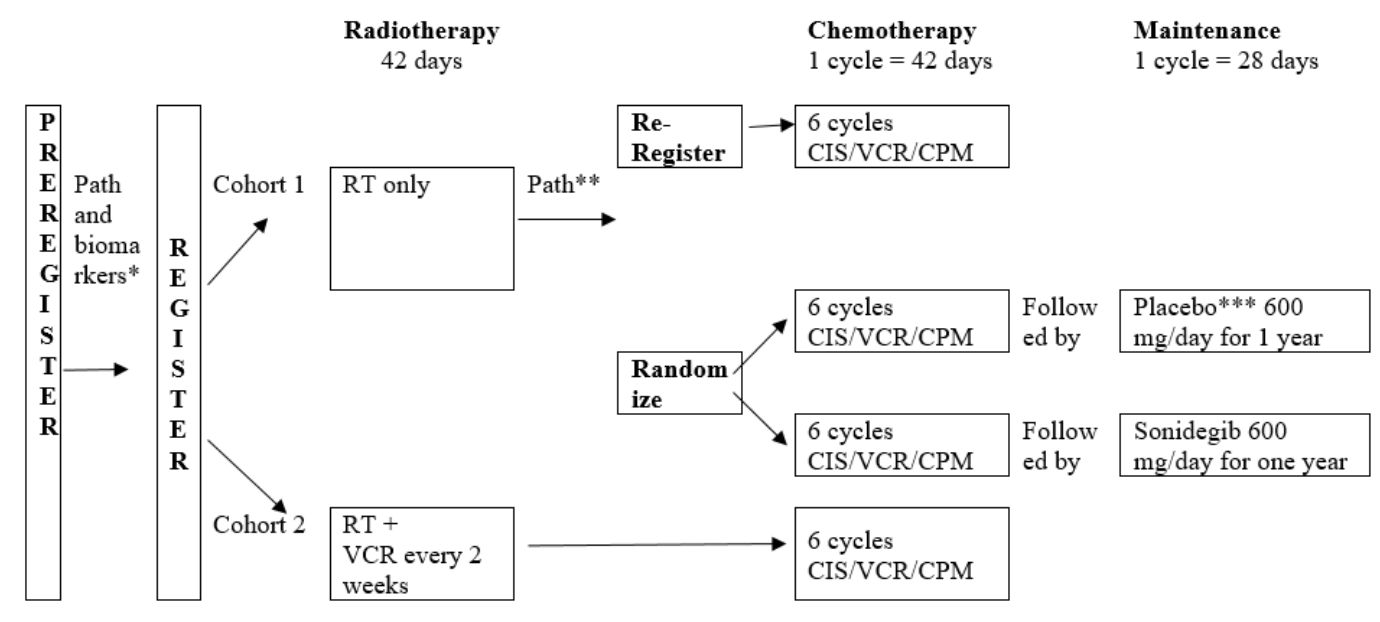

Figure 1. Overall schema of the AMBUSH trial (A072001) for patients 18 years of age at diagnosis or older with medulloblastoma or pineal embryonal tumors. * Preregister on study and begin clinical staging, RT plan preparation. Central pathology review and biomarker assays: IHC, DNA seq, CNA and clinical staging (postoperative brain MRI, spinal MRI, CSF analysis) required to assign to cohort: Cohort 1: average risk MB (non-SHH or SHH arms); Cohort 2: high risk MB or any PET. ${ }^{* *}$ Final integrated pathological diagnosis including results of DNA methylation for MB subgroup confirmation (SHH vs. Non-SHH-Group 4, WNT). ${ }^{* * *}$ Patients receiving placebo who relapse will be allowed to crossover. Abbreviations: RT: radiotherapy; MB: medulloblastoma; IHC: immunohistochemistry; DNA seq: DNA sequencing; CNA: copy number assessment; $\mathrm{SHH}$ : sonic hedgehog; yo: years old; GTR: gross total resection; NTR: near total resection; M0: no metastatic disease; M1-3: any metastatic disease; CSI: craniospinal irradiation; q2wk: every other week; CIS: cisplatin; VCR: vincristine; CPM: cyclophosphamide; PS: performance status; XRT: $x$-ray radiotherapy; PRT: proton radiotherapy.

While the nonrandomized arms will be analyzed in a descriptive manner, the primary analysis will be on those average-risk SHH-MB patients randomized to $\mathrm{SHH}$ pathway inhibition versus placebo. Here, this study design will provide $80 \%$ power to detect a true hazard ratio of 0.45 for PFS (corresponding to 5-year PFS rate of 70\% vs. 85\%), with a one-sided Type I error constraint of 0.10 and an interim analysis for futility conducted after $50 \%$ of expected events are observed.

\section{Objectives}

The primary objective is to evaluate the ability of SHH pathway inhibition maintenance therapy to improve progression-free survival (PFS), compared to placebo, in average risk patients with SHH-MB. Secondary objectives will include evaluating PFS in average-risk non-SHH-MB patients, high-risk $\mathrm{MB}$, and pineal embryonal tumor patients with the aim to describe other clinical outcomes in these less-common subtypes.

\section{Accrual Goal}

A total of 108 patients will be accrued for randomization to the average-risk SHHMB arm. The other groups will be open to accrual for the full duration of accrual to the randomized arms. It is estimated that a total of 20-40 patients will be registered to each of the non-randomized arms.

\section{Translational Research}

This trial presents a unique and highly valuable opportunity to understand the full spectrum of patient-centered outcomes, disease correlatives and treatment related morbidities. Patients will undergo specific evaluations at baseline and subsequent visits to facilitate a greater understanding of patient-centered outcomes. The planned tests and observations are summarized in Table 3. 
Table 3. Baseline and subsequent tests and observations for patients enrolled on the AMBUSH Study.

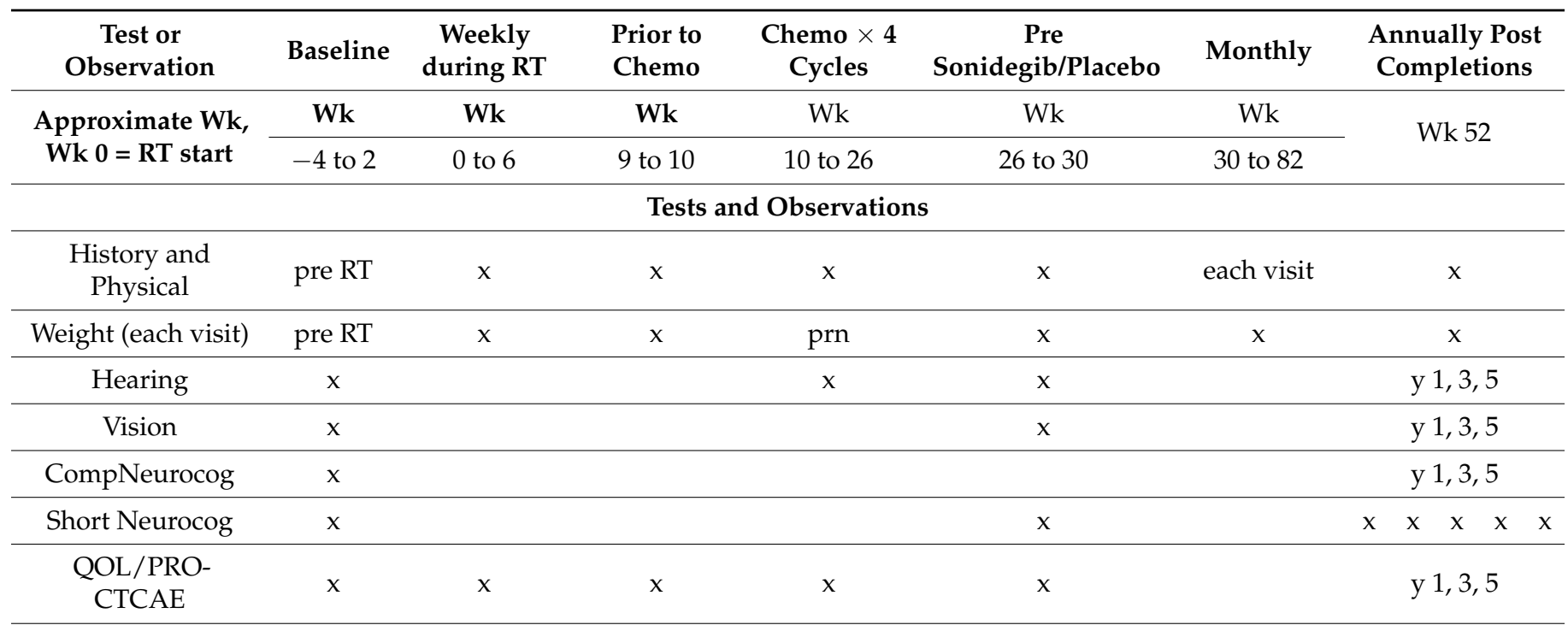

\section{Laboratory Studies}

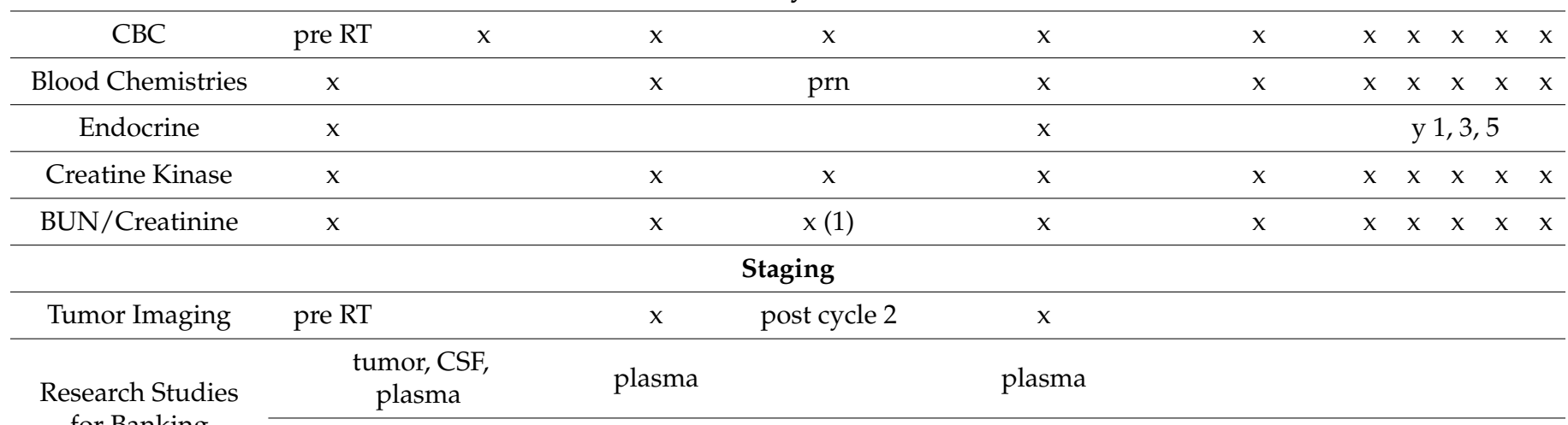

n.b. $x$ denotes when the test or observation will be required on the protocol. Abbreviations: Wk: week; RT: radiotherapy; chemo: chemotherapy; Comp Neurocog: comprehensive neurocognitive testing; Short Neurocog: Short neurocognitive testing; QOL: quality of life; PRO: patient reported outcomes; CBC: complete blood count; BUN: blood urea nitrogen; CSF: cerebrospinal fluid; prn: as needed; y: year.

\subsection{Neurocognitive Function}

Most people treated for MB survive at least 10 years [37,38]. Much of the literature concerning neurocognitive functioning among MB survivors involves children or individuals treated during childhood. Few studies of adult MB survivors have been conducted. Harrison et al., conducted a cross-sectional study of 27 patients treated for MB during early adulthood in which $25-30 \%$ of patients displayed impaired executive function and newlearning performance that correlated with the amount of chemotherapy cycles received [39]. Dirven et al. reported on 28 patients treated with radiation and chemotherapy. Working memory and attention were generally impaired after treatment and remained compromised during the follow-up period. In contrast, executive function and information processing speed improved over the follow-up period [40].

These investigations are limited by relatively small sample sizes, but they are representative of the limited literature concerning MB in adults. They suggest that treatment of MB corresponds with attenuated executive function, working memory, and new learning. Patients enrolled on this study will have serial neurocognitive testing to determine frequency and extent of neurologic compromise and evaluate the contributing factors. 


\subsection{Health Related Quality of Life}

There is very little information about the health-related quality of life outcomes for older patients treated for $\mathrm{MB}$ or pineal region tumors. The current trial presents a significant opportunity to assess health-related quality of life prospectively and systematically in adults receiving chemoradiation following surgery and for patients with SHH-mutated tumors randomized to the sonidegib arm with this addition of a SMO inhibitor added to standard of care chemoradiation. The EORTC QLQ-30 and QLQ-BN-20 questionnaires were chosen for the current study to harmonize with companion studies and take 15-20 min to complete. These longitudinal patient-reported outcome assessments will coincide with imaging assessment visits to minimize burden to the patient. Additionally, PRO-CTCAE will also be assessed during treatment. The study of patient-reported symptom burden and health-related quality of life, which encompasses the patients' perception of their physical, psychological, and social well-being, are critically important in better understanding the implications of the proposed treatment on living with this disease and through its treatment, in both the acute and long-term settings, above and beyond the disease-centered outcomes of PFS and OS.

\subsection{Neuroendocrine, Auditory, and Visual Functions}

MB treatment can affect normal neuroendocrine, auditory, and visual functions with the use of CSI and chemotherapy such as cisplatinum [41-46]. In this study we will collect baseline and subsequent functions to objectively evaluate subsequent morbidity in these patient cohorts. Dose-volume relationships with radiotherapy and chemotherapy will be determined.

\subsection{Radiotherapy Modality}

Retrospective studies have suggested improved tolerance of radiotherapy and subsequent chemotherapy with the use of proton therapy [47]. In children there is evidence of reduced auditory, endocrine, and neurocognitive toxicities when proton therapy is used in comparison to X-ray based therapies [43-48]. In this study we will stratify patients in the randomized arm based on whether they are treated with proton beam therapy or X-ray based radiation and note radiotherapy modality in all patients to prospectively assess whether findings noted in the studies above hold true in the adult population as well.

\subsection{Effect of Memantine}

Memantine has been reported to reduce neurocognitive morbidity in patients receiving whole brain radiotherapy for brain metastasis and now has become a standard of care [49-51]. Similarly, memantine is now being studied in children to reduce radiation related toxicities (NCT 03194906, NCT 04217694). In this study, use of memantine during radiotherapy will be used as a stratification factor for randomization and will be noted in all patients to determine whether neurocognitive outcomes or tumor control are affected by its use.

\subsection{CSF and Plasma Banking}

CSF and plasma will be obtained in a serial fashion for banking. Studies are planned to determine whether liquid biopsy markers such as circulating tumor DNA, extracellular vesicles, or other markers can predict tumor recurrence or other high-risk features.

\subsection{Comparison to Contemporaneous Trials}

The AMBUSH study will overlap with an EORTC adult MB studies in Europe. Though the studies are not identical, there will be a unique opportunity to compare outcomes in the average-risk patients. Between the two studies, even though each cohort is relatively small, we will be simultaneously answering whether concurrent or maintenance SMO inhibition is tolerated and/or effective. In addition, we will have prospective data collected that could be merged to evaluate other outcomes such as hearing loss, quality of life or cognition. Similarly, this will provide a unique opportunity to compare findings with 
ongoing pediatric trials that are building on MB subtype tailored treatment algorithms and toxicity reduction efforts.

\section{Conclusions}

This trial aims to set a standard of care for treatment of AYA and adult MB. It incorporates a strategic and innovative molecular targeted agent for the most common type of $\mathrm{MB}$ in this patient cohort $(\mathrm{SHH})$. We will be able to prospectively determine if this cohort of older patients has similar outcomes to the pediatric population when treated with CSI and adjuvant chemotherapy. The trial will include Health related quality of life (HRQOL), neurocognitive, endocrine, auditory, and visual assessments to evaluate full cohort outcomes as well as relationships with normal tissue dose distributions.

Author Contributions: Conceptualization, A.M., H.S., M.P.-P. and E.G.; methodology, A.M., C.G., S.G. and E.G.; resources, writing-original draft preparation: A.M.; writing-review and editing, H.S., M.P.-P., K.L., K.A., L.S.H., A.R.L., M.R.B., H.E.L., B.V.N., S.L.S., S.G., C.G. and E.G. All authors have read and agreed to the published version of the manuscript.

Funding: This research received no external funding.

Acknowledgments: Alliance for Clinical Trial in Oncology Protocol Development Group.

Conflicts of Interest: The academic funders and Sun Pharmaceuticals Industries Ltd. had no role in the design of the study and will have no role in the collection, analyses, or interpretation of data, in the writing of manuscripts, or in the decision to publish results. The authors declare no conflict of interest.

\section{References}

1. Giordana, M.T.; Schiffer, P.; Lanotte, M.; Girardi, P.; Chio, A. Epidemiology of adult medulloblastoma. Int. J. Cancer 1999, 80, 689-692. [CrossRef]

2. Ostrom, Q.T.; Gittleman, H.; Fulop, J.; Liu, M.; Blanda, R.; Kromer, C.; Wolinsky, Y.; Kruchko, C.; Barnholtz-Sloan, J.S. CBTRUS Statistical Report: Primary Brain and Other Central Nervous System Tumors Diagnosed in the United States in 2009-2013. Neuro Oncol. 2016, 18, v1-v75. [CrossRef]

3. Gajjar, A.; Chintagumpala, M.; Ashley, D.; Kellie, S.; Kun, L.E.; Merchant, T.E.; Woo, S.; Wheeler, G.; Ahern, V.; Krasin, M.J.; et al. Risk-adapted craniospinal radiotherapy followed by high-dose chemotherapy and stem-cell rescue in children with newly diagnosed medulloblastoma (St Jude Medulloblastoma-96): Long-term results from a prospective, multicentre trial. Lancet Oncol. 2006, 7, 813-820. [CrossRef]

4. Packer, R.J.; Gajjar, A.; Vezina, G.; Rorke-Adams, L.; Burger, P.C.; Robertson, P.L.; Bayer, L.; LaFond, D.; Donahue, B.R.; Marymont, M.H.; et al. Phase III Study of Craniospinal Radiation Therapy Followed by Adjuvant Chemotherapy for Newly Diagnosed Average-Risk Medulloblastoma. J. Clin. Oncol. 2006, 24, 4202-4208. [CrossRef] [PubMed]

5. Von Bueren, A.O.; Kortmann, R.-D.; Von Hoff, K.; Friedrich, C.; Mynarek, M.; Müller, K.; Goschzik, T.; Mühlen, A.Z.; Gerber, N.; Warmuth-Metz, M.; et al. Treatment of Children and Adolescents With Metastatic Medulloblastoma and Prognostic Relevance of Clinical and Biologic Parameters. J. Clin. Oncol. 2016, 34, 4151-4160. [CrossRef]

6. Lannering, B.; Rutkowski, S.; Doz, F.; Pizer, B.; Gustafsson, G.; Navajas, A.; Massimino, M.; Reddingius, R.; Benesch, M.; Carrie, C.; et al. Hyperfractionated Versus Conventional Radiotherapy Followed by Chemotherapy in Standard-Risk Medulloblastoma: Results From the Randomized Multicenter HIT-SIOP PNET 4 Trial. J. Clin. Oncol. 2012, 30, 3187-3193. [CrossRef]

7. Michalski, J.M.; Janss, A.J.; Vezina, L.G.; Smith, K.S.; Billups, C.A.; Burger, P.C.; Embry, L.M.; Cullen, P.L.; Hardy, K.K.; Pomeroy, S.L.; et al. Children's Oncology Group Phase III Trial of Reduced-Dose and Reduced-Volume Radiotherapy With Chemotherapy for Newly Diagnosed Average-Risk Medulloblastoma. J. Clin. Oncol. 2021, 39, 2685-2697. [CrossRef]

8. Thomas, P.R.M.; Deutsch, M.; Kepner, J.L.; Boyett, J.M.; Krischer, J.; Aronin, P.; Albright, L.; Allen, J.; Packer, R.J.; Linggood, R.; et al. Low-Stage Medulloblastoma: Final Analysis of Trial Comparing Standard-Dose With Reduced-Dose Neuraxis Irradiation. J. Clin. Oncol. 2000, 18, 3004-3011. [CrossRef]

9. Cosman, R.; Brown, C.; De Braganca, K.; Khasraw, M. Patterns of care in adult medulloblastoma: Results of an international online survey. J. Neuro-Oncology 2014, 120, 125-129. [CrossRef]

10. Patil, R.; Gupta, T.; Maitre, M.; Dasgupta, A.; Sahay, A.; Epari, S.; Shirsat, N.; Chatterjee, A.; Krishnatry, R.; Goda, J.S.; et al. Clinical Audit of Survival Outcomes and Prognostic Factors in Adolescents and Adults with Medulloblastoma. J. Adolesc. Young-Adult Oncol. 2021. [CrossRef] [PubMed]

11. Penas-Prado, M.; Theeler, B.J.; Cordeiro, B.; Dunkel, I.J.; Hau, P.; Mahajan, A.; Robinson, G.W.; Willmarth, N.; Aboud, O.; Aldape, K.; et al. Proceedings of the Comprehensive Oncology Network Evaluating Rare CNS Tumors (NCI-CONNECT) Adult Medulloblastoma Workshop. Neuro-Oncology Adv. 2020, 2, vdaa097. [CrossRef] 
12. Brandes, A.A.; Ermani, M.; Amista, P.; Basso, U.; Vastola, F.; Gardiman, M.; Iuzzolino, P.; Turazzi, S.; Rotilio, A.; Volpin, L.; et al. The treatment of adults with medulloblastoma: A prospective study. Int. J. Radiat. Oncol. 2003, 57, 755-761. [CrossRef]

13. Northcott, P.A.; Korshunov, A.; Pfister, S.; Taylor, M. The clinical implications of medulloblastoma subgroups. Nat. Rev. Neurol. 2012, 8, 340-351. [CrossRef]

14. Ramaswamy, V.; Taylor, M. Medulloblastoma: From Myth to Molecular. J. Clin. Oncol. 2017, 35, 2355-2363. [CrossRef]

15. Schwalbe, E.; Lindsey, J.C.; Nakjang, S.; Crosier, S.; Smith, A.J.; Hicks, D.; Rafiee, G.; Hill, R.M.; Iliasova, A.; Stone, T.; et al. Novel molecular subgroups for clinical classification and outcome prediction in childhood medulloblastoma: A cohort study. Lancet Oncol. 2017, 18, 958-971. [CrossRef]

16. Sengupta, S.; Krummel, D.P.; Pomeroy, S. The evolution of medulloblastoma therapy to personalized medicine. F1000Research 2017, 6, 490. [CrossRef]

17. Northcott, P.A.; Dubuc, A.M.; Pfister, S.; Taylor, M.D. Molecular subgroups of medulloblastoma. Expert Rev. Neurother. 2012, 12, 871-884. [CrossRef]

18. Remke, M.; Hielscher, T.; Northcott, P.A.; Witt, H.; Ryzhova, M.; Wittmann, A.; Benner, A.; von Deimling, A.; Scheurlen, W.; Perry, A.; et al. Adult Medulloblastoma Comprises Three Major Molecular Variants. J. Clin. Oncol. 2011, 29, 2717-2723. [CrossRef] [PubMed]

19. Zhao, F.; Ohgaki, H.; Xu, L.; Giangaspero, F.; Li, C.; Li, P.; Yang, Z.; Wang, B.; Wang, X.; Wang, Z.; et al. Molecular subgroups of adult medulloblastoma: A long-term single-institution study. Neuro-Oncology 2016, 18, 982-990. [CrossRef] [PubMed]

20. Coltin, H.; Sundaresan, L.; Smith, K.S.; Skowron, P.; Massimi, L.; Eberhart, C.G.; Schreck, K.C.; Gupta, N.; Weiss, W.A.; Tirapelli, D.; et al. Subgroup and subtype-specific outcomes in adult medulloblastoma. Acta Neuropathol. 2021, 142, 859-871. [CrossRef] [PubMed]

21. Ellison, D.W.; Dalton, J.; Kocak, M.; Nicholson, S.L.; Fraga, C.; Neale, G.; Kenney, A.M.; Brat, D.J.; Perry, A.; Yong, W.H.; et al. Medulloblastoma: Clinicopathological correlates of SHH, WNT, and non-SHH/WNT molecular subgroups. Acta Neuropathol. 2011, 121, 381-396. [CrossRef]

22. Zhukova, N.; Ramaswamy, V.; Remke, M.; Pfaff, E.; Shih, D.J.H.; Martin, D.C.; Castelo-Branco, P.; Baskin, B.; Ray, P.N.; Bouffet, E.; et al. Subgroup-Specific Prognostic Implications of TP53 Mutation in Medulloblastoma. J. Clin. Oncol. 2013, 31, $2927-2935$. [CrossRef] [PubMed]

23. Herrlinger, U.; Steinbrecher, A.; Rieger, J.; Hau, P.; Kortmann, R.D.; Meyermann, R.; Schabet, M.; Bamberg, M.; Dichgans, J.; Bogdahn, U.; et al. Adult medulloblastoma: Prognostic factors and response to therapy at diagnosis and at relapse. J. Neurol. 2005, 252, 291-299. [CrossRef]

24. Takase, H.; Tanoshima, R.; Singla, N.; Nakamura, Y.; Yamamoto, T. Pineal parenchymal tumor of intermediate differentiation: A systematic review and contemporary management of 389 cases reported during the last two decades. Neurosurg Rev. 2021. online ahead of print. [CrossRef]

25. Jakacki, R.I.; Zeltzer, P.M.; Boyett, J.M.; Albright, A.L.; Allen, J.C.; Geyer, J.R.; Rorke, L.B.; Stanley, P.; Stevens, K.R.; Wisoff, J. Survival and prognostic factors following radiation and/or chemotherapy for primitive neuroectodermal tumors of the pineal region in infants and children: A report of the Childrens Cancer Group. J. Clin. Oncol. 1995, 13, 1377-1383. [CrossRef]

26. Massimino, M.; Sunyach, M.P.; Barretta, F.; Gandola, L.; Garegnani, A.; Pecori, E.; Spreafico, F.; Bonneville-Levard, A.; Meyronet, D.; Mottolese, C.; et al. Reduced-dose craniospinal irradiation is feasible for standard-risk adult medulloblastoma patients. J. Neuro-Oncology 2020, 148, 619-628. [CrossRef] [PubMed]

27. Paterson, E.; Farr, R.F. Cerebellar Medulloblastoma: Treatment by Irradiation of the Whole Central Nervous System. Acta Radiol. 1953, 39, 323-336. [CrossRef] [PubMed]

28. Friedrich, C.; von Bueren, A.O.; von Hoff, K.; Kwiecien, R.; Pietsch, T.; Warmuth-Metz, M.; Hau, P.; Deinlein, F.; Kuehl, J.; Kortmann, R.D.; et al. Treatment of adult nonmetastatic medulloblastoma patients according to the paediatric HIT 2000 protocol: A prospective observational multicentre study. Eur. J. Cancer 2012, 49, 893-903. [CrossRef] [PubMed]

29. Majd, N.K.; Mastall, M.; Lin, H.; Dibaj, S.S.; Hess, K.R.; Yuan, Y.; Garcia, M.M.; Fuller, G.N.; Alfaro, K.D.; Gule-Monroe, M.K.; et al. Clinical characterization of adult medulloblastoma and the effect of first-line therapies on outcome; The MD Anderson Cancer Center experience. Neurooncol Adv. 2021, 3, vdab079. [CrossRef]

30. Beier, D.; Proescholdt, M.; Reinert, C.; Pietsch, T.; Jones, D.T.W.; Pfister, S.M.; Hattingen, E.; Seidel, C.; Dirven, L.; Luerding, R.; et al. Multicenter pilot study of radiochemotherapy as first-line treatment for adults with medulloblastoma (NOA-07). Neuro-Oncology 2017, 20, 400-410. [CrossRef] [PubMed]

31. Von Bueren, A.O.; Friedrich, C.; Von Hoff, K.; Kwiecien, R.; Müller, K.; Pietsch, T.; Warmuth-Metz, M.; Hau, P.; Benesch, M.; Kuehl, J.; et al. Metastatic medulloblastoma in adults: Outcome of patients treated according to the HIT2000 protocol. Eur. J. Cancer 2015, 51, 2434-2443. [CrossRef]

32. Carballo, G.B.; Honorato, J.R.; De Lopes, G.P.F.; Spohr, T.C.L.D.S.E. A highlight on Sonic hedgehog pathway. Cell Commun. Signal. 2018, 16, 11. [CrossRef]

33. Kieran, M.W. Targeted treatment for sonic hedgehog-dependent medulloblastoma. Neuro-Oncology 2014, 16, 1037-1047. [CrossRef]

34. Kool, M.; Jones, D.T.W.; Jaeger, N.; Northcott, P.A.; Pugh, T.J.; Hovestadt, V.; Piro, R.M.; Esparza, L.A.; Markant, S.L.; Remke, M.; et al. Genome Sequencing of SHH Medulloblastoma Predicts Genotype-Related Response to Smoothened Inhibition. Cancer Cell 2014, 25, 393-405. [CrossRef] 
35. Kieran, M.W.; Chisholm, J.; Casanova, M.; Brandes, A.A.; Aerts, I.; Bouffet, E.; Bailey, S.; Leary, S.; Macdonald, T.J.; Mechinaud, F.; et al. Phase I study of oral sonidegib (LDE225) in pediatric brain and solid tumors and a phase II study in children and adults with relapsed medulloblastoma. Neuro-Oncology 2017, 19, 1542-1552. [CrossRef]

36. Dummer, R.; Guminksi, A.; Gutzmer, R.; Lear, J.T.; Lewis, K.D.; Chang, A.L.S.; Combemale, P.; Dirix, L.; Kaatz, M.; Kudchadkar, R.; et al. Long-term efficacy and safety of sonidegib in patients with advanced basal cell carcinoma: 42-month analysis of the phase II randomized, double-blind BOLT study. Br. J. Dermatol. 2020, 182, 1369-1378. [CrossRef] [PubMed]

37. Khanna, V.; Achey, R.L.; Ostrom, Q.; Block-Beach, H.; Kruchko, C.; Barnholtz-Sloan, J.S.; de Blank, P. Incidence and survival trends for medulloblastomas in the United States from 2001 to 2013. J. Neuro-Oncology 2017, 135, 433-441. [CrossRef]

38. Li, Q.; Dai, Z.; Cao, Y.; Wang, L. Comparing children and adults with medulloblastoma: A SEER based analysis. Oncotarget 2018, 9, 30189-30198. [CrossRef] [PubMed]

39. Harrison, R.A.; Kesler, S.R.; Johnson, J.; Penas-Prado, M.; Sullaway, C.M.; Wefel, J.S. Neurocognitive dysfunction in adult cerebellar medulloblastoma. Psycho-Oncology 2018, 28, 131-138. [CrossRef] [PubMed]

40. Dirven, L.; Luerding, R.; Beier, D.; Bumes, E.; Reinert, C.; Seidel, C.; Bonsanto, M.M.; Bremer, M.; Rieken, S.; Combs, S.E.; et al. Neurocognitive functioning and health-related quality of life in adult medulloblastoma patients: Long-term outcomes of the NOA-07 study. J. Neuro-Oncology 2020, 148, 117-130. [CrossRef]

41. Gibson, T.M.; Mostoufi-Moab, S.; Stratton, K.L.; Leisenring, W.; Barnea, D.; Chow, E.; Donaldson, S.S.; Howell, R.M.; Hudson, M.M.; Mahajan, A.; et al. Temporal patterns in the risk of chronic health conditions in survivors of childhood cancer diagnosed 1970-99: A report from the Childhood Cancer Survivor Study cohort. Lancet Oncol. 2018, 19, 1590-1601. [CrossRef]

42. Moeller, B.J.; Chintagumpala, M.; Philip, J.J.; Grosshans, D.R.; McAleer, M.F.; Woo, S.Y.; Gidley, P.W.; Vats, T.S.; Mahajan, A Low early ototoxicity rates for pediatric medulloblastoma patients treated with proton radiotherapy. Radiat. Oncol. 2011, 6, 58. [CrossRef] [PubMed]

43. Paulino, A.C.; Mahajan, A.; Ye, R.; Grosshans, D.R.; Okcu, M.F.; Su, J.; McAleer, M.F.; McGovern, S.; Mangona, V.A.; Chintagumpala, M. Ototoxicity and cochlear sparing in children with medulloblastoma: Proton vs. photon radiotherapy. Radiother. Oncol. 2018, 128, 128-132. [CrossRef] [PubMed]

44. Aldrich, K.D.; Horne, V.E.; Bielamowicz, K.; Sonabend, R.Y.; Scheurer, M.E.; Paulino, A.C.; Mahajan, A.; Chintagumpala, M.; Okcu, M.F.; Brown, A.L. Comparison of hypothyroidism, growth hormone deficiency, and adrenal insufficiency following proton and photon radiotherapy in children with medulloblastoma. J. Neuro-Oncology 2021, 155, 93-100. [CrossRef]

45. Bielamowicz, K.; Okcu, M.F.; Sonabend, R.; Paulino, A.C.; Hilsenbeck, S.G.; Dreyer, Z.; Suzawa, H.; Bryant, R.; Adesina, A.; Dauser, R.; et al. Hypothyroidism after craniospinal irradiation with proton or photon therapy in patients with medulloblastoma. Pediatr. Hematol. Oncol. 2018, 35, 257-267. [CrossRef] [PubMed]

46. Vatner, R.E.; Niemierko, A.; Misra, M.; Weyman, E.A.; Goebel, C.P.; Ebb, D.H.; Jones, R.M.; Huang, M.S.; Mahajan, A.; Grosshans, D.R.; et al. Endocrine Deficiency As a Function of Radiation Dose to the Hypothalamus and Pituitary in Pediatric and Young Adult Patients With Brain Tumors. J. Clin. Oncol. 2018, 36, 2854-2862. [CrossRef]

47. Brown, A.P.; Barney, C.L.; Grosshans, D.R.; McAleer, M.F.; de Groot, J.F.; Puduvalli, V.K.; Tucker, S.L.; Crawford, C.N.; Khan, M.; Khatua, S.; et al. Proton Beam Craniospinal Irradiation Reduces Acute Toxicity for Adults With Medulloblastoma. Int. J. Radiat. Oncol. 2013, 86, 277-284. [CrossRef]

48. Zhang, R.; Howell, R.M.; Taddei, P.J.; Giebeler, A.; Mahajan, A.; Newhauser, W.D. A comparative study on the risks of radiogenic second cancers and cardiac mortality in a set of pediatric medulloblastoma patients treated with photon or proton craniospinal irradiation. Radiother Oncol. 2014, 113, 84-88. [CrossRef]

49. Brown, P.D.; Gondi, V.; Pugh, S.; Tome, W.A.; Wefel, J.S.; Armstrong, T.S.; Bovi, J.A.; Robinson, C.; Konski, A.; Khuntia, D.; et al Hippocampal Avoidance During Whole-Brain Radiotherapy Plus Memantine for Patients With Brain Metastases: Phase III Trial NRG Oncology CC001. J. Clin. Oncol. 2020, 38, 1019-1029. [CrossRef]

50. Laack, N.N.; Pugh, S.L.; Brown, P.D.; Fox, S.; Wefel, J.S.; Meyers, C.; Choucair, A.; Khuntia, D.; Suh, J.H.; Roberge, D.; et al. The association of health-related quality of life and cognitive function in patients receiving memantine for the prevention of cognitive dysfunction during whole-brain radiotherapy. Neuro-Oncology Pract. 2018, 6, 274-282. [CrossRef]

51. Brown, P.D.; Pugh, S.; Laack, N.N.; Wefel, J.S.; Khuntia, D.; Meyers, C.; Choucair, A.; Fox, S.; Suh, J.H.; Roberge, D.; et al. Memantine for the prevention of cognitive dysfunction in patients receiving whole-brain radiotherapy: A randomized, doubleblind, placebo-controlled trial. Neuro-Oncology 2013, 15, 1429-1437. [CrossRef] [PubMed] 